\title{
Geriatric assessment is superior to oncologists' clinical judgement in identifying frailty
}

Lene Kirkhus $^{\star, 1,2}$, Jūrate Šaltyte Benth ${ }^{1,2,3}$, Siri Rostoft ${ }^{2,4}$, Bjørn Henning Grønberg ${ }^{5,6}$, Marianne J Hjermstad ${ }^{7,8}$, Geir Selbæk ${ }^{1,9,10}$, Torgeir B Wyller ${ }^{2,4}$, Magnus Harneshaug ${ }^{1,2}$ and Marit S Jordhøy 2,11

${ }^{1}$ The Centre for Old Age Psychiatry Research, Innlandet Hospital Trust, PO box 68, Ottestad 2313, Norway; ${ }^{2}$ Institute of Clinical Medicine, Faculty of Medicine, University of Oslo, PO box 4956 Nydalen, Oslo 0424, Norway; ${ }^{3}$ HØKH Research Centre, Akershus University Hospital, PO box 1000, Lørenskog 1478, Norway; ${ }^{4}$ Department of Geriatric Medicine, Oslo University Hospital, P.O box 4956 Nydalen, Oslo 0424, Norway; ${ }^{5}$ The Cancer Clinic, St Olavs Hospital, Trondheim University Hospital, PO box 3250 Sluppen, Trondheim 7006, Norway; ${ }^{6}$ Department of Cancer Research and Molecular Medicine, NTNU, Norwegian University of Science and Technology, PO box 8905, Trondheim 7491, Norway; ${ }^{7}$ Regional Advisory Unit for Palliative Care, Department of Oncology, Oslo University Hospital, PO box 4956 Nydalen, Oslo 0424, Norway; ${ }^{8}$ European Palliative Care Research Centre, Department of Cancer Research and Molecular Medicine, NTNU, Norwegian University of Science and Technology, Trondheim 7491, Norway; ${ }^{9}$ Norwegian Advisory Unit on Ageing and Health, Vestfold Hospital Trust, PO box 2136, Tønsberg 3103, Norway; ${ }^{10}$ Institute of Health and Society, Faculty of Medicine, University of Oslo, PO box 1130 Blindern, Oslo 0318, Norway and ${ }^{11}$ The Cancer Unit, Innlandet Hospital Trust, Hamar Hospital, Skolegata 32, Hamar 2326, Norway

Background: Frailty is a syndrome associated with increased vulnerability and an important predictor of outcomes in older cancer patients. Systematic assessments to identify frailty are seldom applied, and oncologists' ability to identify frailty is scarcely investigated.

Methods: We compared oncologists' classification of frailty (onc-frail) based on clinical judgement with a modified geriatric assessment $(m G A)$, and investigated associations between frailty and overall survival. Patients $\geqslant 70$ years referred for medical cancer treatment were eligible. mGA-frailty was defined as impairment in at least one of the following: daily activities, comorbidity, polypharmacy, physical function or at least one geriatric syndrome (cognitive impairment, depression, malnutrition, falls).

Results: Three hundred and seven patients were enroled, 288 (94\%) completed the mGA, 286 (93\%) were rated by oncologists. Median age was 77 years, $56 \%$ had metastases, 85\% performance status (PS) 0-1. Overall, 104/286 (36\%) were onc-frail and 140/288 (49\%) mGA-frail, the agreement was fair (kappa value 0.30 ( $95 \% \mathrm{Cl} 0.19$; 0.41)), and $67 \mathrm{mGA}$-frail patients who frequently had localised disease, good PS and received curative treatment, were missed by the oncologists. Only mGA-frailty was independently prognostic for survival (HR 1.61,95\% $\mathrm{Cl} 1.14 ; 2.27 ; P=0.007)$.

Conclusions: Systematic assessment of geriatric domains is needed to aid oncologists in identifying frail patients with poor survival. 
Approximately half of patients diagnosed with cancer are $\geqslant 70$ years, and owing to an aging population the number of older cancer patients is rapidly increasing (Syse, 2012; Cancer Research UK, 2016). The heterogenic health status of this large cohort of patients complicates treatment decisions. Age-related decrease in physiological reserves and co-existing problems, such as physical and cognitive impairments and comorbidities that may affect both treatment and outcomes (CloughGorr et al, 2010; Kristjansson et al, 2010), vary considerably between individuals. For appropriate treatment planning it is paramount to identify those who are fit and may tolerate standard treatment, and those who are frail and may profit from less-intensive treatment (Balducci and Extermann, 2000).

Frailty is widely recognised as a syndrome of increased vulnerability to adverse changes in health status (Clegg et al, 2013). There is, however, no consensus on how to best identify frail patients. In clinical trials, the Fried Phenotype model or indices based on accumulation of deficits (Huisingh-Scheetz and Walston, 2017) are commonly used. Geriatric assessment (GA) includes a systematic assessment of areas where problems are frequent in older age, such as comorbidity, medication, physical and cognitive function, and is the most frequently applied approach to assess vulnerability and frailty in cancer patients (Handforth et al, 2015). Consensus statements on what GA in this setting should include are, however, not entirely consistent (Wildiers et al, 2014; Mohile et al, 2015) and there are no agreed criteria to define frailty based on GA. Thus, varying domains and thresholds have been used (Handforth et al, 2015), and several studies have applied frailty criteria as proposed by Balducci and Extermann, 2000, or a modification of these (Basso et al, 2008; Tucci et al, 2009; Kristjansson et al, 2010). Frailty defined according to this approach is demonstrated to be prognostic for survival (Basso et al, 2008; Tucci et al, 2009; Ommundsen et al, 2014). Performing a full GA is time and resource consuming, and although highly recommended, is yet to be established in routine clinical practice (Magnuson et al, 2016). Easily applicable screening tools have therefore been sought, and some have documented ability to predict survival (Soubeyran et al, 2014). However, compared with a complete GA, none has demonstrated sufficient sensitivity and specificity to reliably identify frail patients (Hamaker et al, 2012). Based on the excellent prognostic performance of simple physician-rated scales such as the Eastern Cooperative Oncology Group Performance Status (PS) (Schiller et al, 2002), few studies have investigated whether physicians' clinical judgement is an equally effective screening tool for frailty (Wedding et al, 2007; Tucci et al, 2009; Clough-Gorr et al, 2010). The results suggest that physicians are more conservative and rate fewer patients as unfit or potentially vulnerable than those identified by GA (Wedding et al, 2007; Tucci et al, 2009; Clough-Gorr et al, 2010). However, two of these studies either used a retrospective evaluation of the patients' overall health at the time of diagnosis (Clough-Gorr et al, 2010) or the physicians' decision for palliative or more intensive treatment for comparison with GA (Tucci et al, 2009). Only one study actually asked the physician to identify frailty, and no treatment outcomes were reported (Wedding et al, 2007). To establish the ability of physicians' frailty ratings to predict outcomes, i.e., in comparison with GA, prospective comparative studies are needed.

In the present study we aimed to (1) compare oncologists' classification of frailty with a systematic modified geriatric assessment (mGA) of frailty, (2) describe what information oncologists emphasise when rating frailty and (3) investigate the associations of these frailty classifications with overall survival (OS).

\section{MATERIALS AND METHODS}

Patients. From January 2013 until April 2015, patients referred for medical cancer treatment were consecutively recruited at eight different outpatient oncology clinics in South East Norway (two university hospitals and six local hospitals). Eligible patients were $\geqslant 70$ years with a histologically confirmed solid tumour (newly diagnosed or first relapse after previous curative treatment). All patients provided written, informed consent. The patients were identified by referral, and oncology nurses with specific training in study procedures performed baseline interviews and mGA-testing, aiming at retrieving all information before treatment started.

Baseline assessments. Medical data were reported by the oncologists and included cancer type (ICD-10), stage of disease (local, locally advanced or metastatic), location of metastatic sites, planned treatment and rating of PS.

We defined our GA as a modified GA (mGA) as it was not performed by a geriatrician or a geriatric team. The mGA included assessment of eight domains. Nutritional status and related symptoms were registered partly by nurses and partly by patients' self-report. Medication, falls, physical and cognitive function were tested and/or registered by the oncology nurses. Comorbidity, activities of daily living (ADL) and depressive symptoms were assessed by patients' self-report.

Nutritional status was assessed using the Patient-Generated Subjective Global Assessment (PG-SGA) (Ottery, 1996; Persson et al, 1999). The PG-SGA includes two parts. One is a patient questionnaire about weight loss and nutritional symptoms, whereas the other is filled in by health professionals and includes a categorisation of a patient's overall nutritional status into (A) well-nourished, (B) moderately malnourished/suspected malnutrition and (C) severely malnourished. Severely malnourished patients are defined as having severe weight loss, visible loss of subcutaneous fat tissue and muscle mass, with or without the presence of oedema. Comorbidity was registered using the Physical Health Section, a subscale of the Older Americans' Resources and Services Questionnaire (OARS) (Fillenbaum and Smyer, 1981; Hurria et al, 2005). The Physical Health Section consists of a list of 15 diseases/conditions as well as a grading of how these conditions affect daily activities. Medication was registered according to the Anatomical Therapeutic Chemical Classification System. Falls were defined as unintentional events resulting in a laying position on the floor, the ground or other lower level, and the number of falls the last 6 months was registered. To screen for deficits in basic ADL we used question 5 ('Do you need help with eating, dressing, washing yourself or using the toilet?') from the 'European Organisation for Research and Treatment of Cancer Quality of Life Core Questionnaire (EORTC QLQ C30)(Aaronson et al, 1993). Questions 1-28 in EORTC QLQ C30 are graded into four categories, 'Not at all', 'A little', 'Quite a bit' and 'Very much'. Depressive symptoms were self-reported on the geriatric depression scale (GDS-15) (Yesavage et al, 1982). This scale consists of 15 items and the total score ranges from 0 to 15 . A higher score indicates more depressive symptoms. Physical performance was tested using the Timed Up and Go test (TUG) (Podsiadlo and Richardson, 1991) which registers the time it takes to rise from an arm chair, walk three metres, turn, walk back and sit down, and patients were instructed to walk at a fast pace (Beauchet et al, 2011). Cognitive function was assessed using the Norwegian Revised Mini Mental State Examination (MMSE-NR) (Folstein et al, 1975). MMSE-NR consists of 20 items and the total score ranges from 0 to 30 . The higher score, the better the cognitive function.

The oncologists were asked to classify the patient as fit, intermediate or frail after their first consultation at baseline. Prior to this, they were blinded for the results from the mGA and not given any specific instructions or training. In case the mGA assessments revealed severe medical problems requiring attention, the nurses gave this information to the patients' oncologist afterwards. 
Table 1. The modified geriatric assessment ${ }^{a}$

\begin{tabular}{|c|c|c|c|c|c|}
\hline Domain & Scale & Range & Rated by & Cutoff value for frailty & Rationale for cutoff values \\
\hline $\begin{array}{l}\text { Activities of } \\
\text { daily living }\end{array}$ & EORTC QLQ-C30 Q5 & & Patient & $\begin{array}{c}\text { If reported yes a little/quite a bit/very } \\
\text { much on the question 'Do you need } \\
\text { help with eating, dressing, washing } \\
\text { yourself or using the toilet' }\end{array}$ & $\begin{array}{l}\text { ADL-deficiencies previously used in } \\
\text { frailty classifications of cancer } \\
\text { patients (Balducci and Extermann, } \\
\text { 2000) }\end{array}$ \\
\hline Comorbidity & OARS $^{c}$ & $\begin{array}{l}\text { 0-15 (Higher } \\
\text { score indicates } \\
\text { more } \\
\text { comorbidities) }\end{array}$ & Patient & $>3$ points & $\begin{array}{l}\text { Threshold for shorter survival in } \\
\text { previous study of cancer patients } \\
\text { (Klepin et al, 2014) }\end{array}$ \\
\hline Physical function & TUG $^{\mathbf{e}}$ & & Nurse & $>14$ seconds & $\begin{array}{c}\text { Similar cut-offs ( } \geqslant 14 />14.5) \text { used to } \\
\text { identify GA deficits in cancer trials } \\
\text { (Owusu et al, 2011; Jolly et al, 2015; } \\
\text { Williams et al, 2015) }\end{array}$ \\
\hline $\begin{array}{l}\text { Nutritional } \\
\text { status }\end{array}$ & PG-SGA ${ }^{h}$ & & Nurse/Patient & $\begin{array}{l}\text { Considered severely malnourished by } \\
\text { nurse or self-reported weight loss } \\
\geqslant 10 \% \text { the last } 6 \text { months. }\end{array}$ & $\begin{array}{l}\text { Weight loss } \geqslant 10 \% \text { the last six } \\
\text { months is generally considered as an } \\
\text { indicator of severe malnutrition } \\
\text { (Nitenberg and Raynard, 2000) }\end{array}$ \\
\hline Falls & & & Nurse & $\begin{array}{c}\text { Patient reports } \geqslant 2 \text { falls the last } 6 \\
\text { months }\end{array}$ & $\begin{array}{c}\text { Previously used to identify GA deficits } \\
\text { in cancer trials (Owusu et al, 2011; } \\
\text { Jolly et al, 2015) }\end{array}$ \\
\hline \multicolumn{6}{|c|}{ 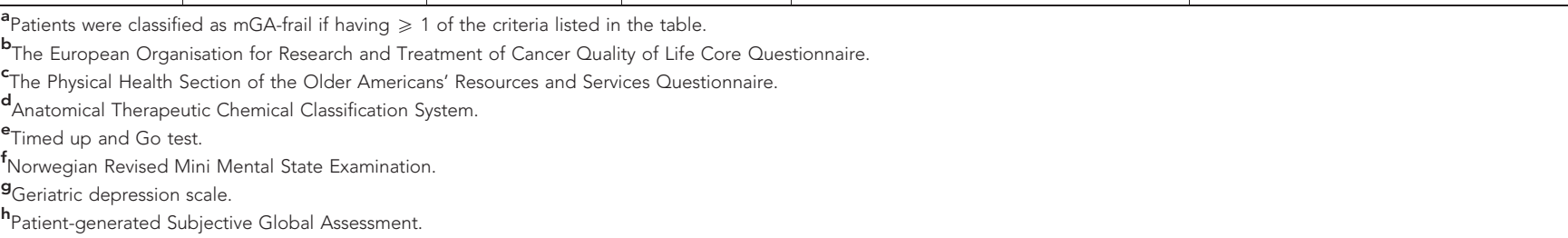 } \\
\hline
\end{tabular}

Information regarding administered cancer treatment and date of death was registered from the patients' medical records. OS was defined as the main outcome. The study was not designed to assess cancer-specific survival.

Statistical analyses. To define frailty according to mGA, we used criteria similar to the modified Balducci criteria formerly applied by Kristjansson et al (2010) and Ommundsen et al (2014), and defined patients as frail if they met one of the following criteria: dependencies in ADL, had significant comorbidity, or one or more geriatric syndromes defined as impaired function according to MMSE (cognitive function), GDS (depression), SGA (malnutrition) or frequency of falls. Furthermore, in accordance with Winograd's criteria for frailty (Winograd et al, 1991) and similar to Kristjansson et al (2010), we included polypharmacy as a criterion, but also added impairment according to TUG, which has been reported as a sensitive and specific measure of frailty (Savva et al, 2013). Pre-defined cutoffs for impaired function within each domain are summarised in Table 1. To enable comparisons between the two procedures for assessment of frailty, and because very few patients were considered frail by the oncologists, their original threefold classification was dichotomised to either onc-non-frail (patients considered fit) or onc-frail (patients considered frail or intermediate).

Demographic and clinical characteristics as well as mGA domains at baseline were presented as median (min, max), mean (standard deviation (SD)), or frequencies and percentages.
Medical and sociodemographic factors were compared between groups by independent sample $t$-tests or $\chi^{2}$-test. The agreement between mGA-non-frail/mGA-frail and the onc-non-frail/onc-frail was assessed by kappa statistics.

Survival time was defined as time from inclusion until death or the last observation date. PS was dichotomised as $0-1$ and 2-4. Treatment was classified into four categories based on the first treatment the patients received; (1) Curative treatment, i.e., patients referred for neoadjuvant treatment, adjuvant treatment after curative surgery or curative radiotherapy (2) Palliative chemotherapy, (3) Other palliative systemic cancer treatment (4) Non-systemic palliative treatment the first two months after inclusion (i.e., radiotherapy, palliative surgery or palliative care). The association between mGA-frailty and OS was first assessed by bivariate Cox regression model. The multiple Cox regression model was estimated to adjust for age, sex, cancer type, PS, stage and treatment. The association between clinicians' judgement of being onc-frail and OS was analysed accordingly. Proportional hazards assumption was assessed by examining Schoenfeld's residuals. Multicollinearity issue was considered by calculating variance inflation factor. Kaplan-Meier OS curves were presented. Significance level was set at 0.05 .

Missing values in MMSE $(n=3)$ and GDS-15 $(n=27)$ were imputed by drawing one random number per value from the empirical distribution based on non-missing values. In total, 31 patients had one or several missing items in the OARS subscale. Missing items on the OARS subscale were imputed by retrieving information from hospital charts. 
Table 2. Baseline patient characteristics according to the mGA and the oncologists' classification

\begin{tabular}{|c|c|c|c|c|c|c|c|c|c|c|c|c|}
\hline & \multirow[b]{3}{*}{$N(288)$} & \multirow[b]{3}{*}{$\%$} & \multicolumn{5}{|c|}{ Modified geriatric assessment } & \multicolumn{5}{|c|}{ The oncologists classification } \\
\hline & & & \multicolumn{2}{|c|}{ mGA-frail } & \multicolumn{3}{|c|}{ mGA-non-frail } & \multicolumn{2}{|c|}{ Onc-frail } & \multicolumn{3}{|c|}{ Onc-non-frail } \\
\hline & & & $N(140)$ & $\%$ & $N(148)$ & $\%$ & $P$-value & $N(104)$ & $\%$ & $N(182)$ & $\%$ & $P$-value \\
\hline $\begin{array}{l}\text { Gender } \\
\text { Female }\end{array}$ & 126 & 44 & 64 & 46 & 62 & 42 & $0.513^{b}$ & 43 & 41 & 81 & 45 & $0.604^{b}$ \\
\hline $\begin{array}{l}\text { Cancer type } \\
\text { Colorectal } \\
\text { Lung } \\
\text { Prostate } \\
\text { Other gastrointestinal } \\
\text { Breast } \\
\text { Other }\end{array}$ & $\begin{array}{l}83 \\
59 \\
56 \\
34 \\
30 \\
26\end{array}$ & $\begin{array}{r}29 \\
21 \\
19 \\
12 \\
10 \\
9\end{array}$ & $\begin{array}{r}39 \\
35 \\
22 \\
19 \\
9 \\
16\end{array}$ & $\begin{array}{r}28 \\
25 \\
16 \\
14 \\
6 \\
11\end{array}$ & $\begin{array}{l}44 \\
24 \\
34 \\
15 \\
21 \\
10\end{array}$ & $\begin{array}{r}30 \\
16 \\
23 \\
10 \\
14 \\
7\end{array}$ & $0.045^{b}$ & $\begin{array}{r}18 \\
34 \\
25 \\
8 \\
6 \\
13\end{array}$ & $\begin{array}{r}17 \\
33 \\
24 \\
8 \\
6 \\
13\end{array}$ & $\begin{array}{l}64 \\
25 \\
31 \\
25 \\
24 \\
13\end{array}$ & $\begin{array}{r}35 \\
14 \\
17 \\
14 \\
13 \\
7\end{array}$ & $<0.001^{\mathrm{b}}$ \\
\hline $\begin{array}{l}\text { Stage } \\
\text { Localised } \\
\text { Locally advanced } \\
\text { Distant metastasis }\end{array}$ & $\begin{array}{r}73 \\
55 \\
160\end{array}$ & $\begin{array}{l}25 \\
19 \\
56\end{array}$ & $\begin{array}{l}30 \\
23 \\
87\end{array}$ & $\begin{array}{l}21 \\
16 \\
62\end{array}$ & $\begin{array}{l}43 \\
32 \\
73\end{array}$ & $\begin{array}{l}29 \\
22 \\
49\end{array}$ & $0.091^{b}$ & $\begin{array}{l}12 \\
22 \\
70\end{array}$ & $\begin{array}{l}12 \\
21 \\
67\end{array}$ & $\begin{array}{l}61 \\
32 \\
89\end{array}$ & $\begin{array}{l}34 \\
18 \\
49\end{array}$ & $<0.001^{\mathrm{b}}$ \\
\hline $\begin{array}{l}\text { Treatment } \\
\text { Curative }^{c} \\
\text { Palliative chemotherapy }_{\text {Other palliative systemic cancer treatment }} \\
\text { Non-systemic palliative treatment }{ }^{d}\end{array}$ & $\begin{array}{r}91 \\
126 \\
51 \\
20\end{array}$ & $\begin{array}{r}32 \\
44 \\
18 \\
7\end{array}$ & $\begin{array}{l}31 \\
75 \\
22 \\
12\end{array}$ & $\begin{array}{r}22 \\
54 \\
16 \\
9\end{array}$ & $\begin{array}{r}60 \\
51 \\
29 \\
8\end{array}$ & $\begin{array}{r}41 \\
35 \\
20 \\
5\end{array}$ & $0.002^{b}$ & $\begin{array}{r}14 \\
60 \\
21 \\
9\end{array}$ & $\begin{array}{r}14 \\
58 \\
20 \\
9\end{array}$ & $\begin{array}{r}77 \\
66 \\
30 \\
9\end{array}$ & $\begin{array}{r}42 \\
36 \\
17 \\
5\end{array}$ & $<0.001^{\mathrm{b}}$ \\
\hline $\begin{array}{l}\text { a Independent samples t-test. } \\
\text { b Pearson }^{2} \text {-test. } \\
c_{\text {Referred for neoadjuvant treatment, adjuvant treatm }} \\
d_{\text {Radiotherapy, palliative surgery or palliative care. }} \\
\text { Bold numbers are statistically significant. }\end{array}$ & fter curc & & or curativ & & rapy. & & & & & & & \\
\hline
\end{tabular}

The study was approved by the Regional Committee for Medical and Health Research Ethics South East Norway and was registered at clinicaltrials.gov (NCT01742442).

\section{RESULTS}

Study recruitment and patient characteristics. The approximate time needed to perform the interview and testing by study nurses was $45 \mathrm{~min}$. A total of 307 patients were enroled, 18 had missing baseline questionnaires and one withdrew consent. Thus, 288 (94\%) patients underwent the mGA and 286 (93\%) were assessed by oncologists. All patients were followed until death or last observation date. The median follow-up time was 16.9 months ( $\min 0.6, \max 40$ ). Last observation date was 31 May 2016. By then, 158 (55\%) patients had died.

Baseline characteristics are shown in Table 2. Median age was 77 years ( $\min 70, \max 95), 126(44 \%)$ were females. The most common cancer types were colorectal $(n=83,29 \%)$, lung $(n=59$, $21 \%)$ and prostate cancer $(n=56,19 \%)$, the majority of patients had PS $0-1 \quad(n=244,85 \%)$ and received palliative treatment ( $n=197,68 \%)$. Chemotherapy was the primary systemic treatment for $200(69 \%)$ patients, (palliative $n=126$, adjuvant $n=74$ ). Almost all patients lived at home $(n=275,96 \%)$, and 93 (34\%) of the patients living at home lived alone.

Frailty according to classification procedure. According to mGA, 140 (49\%) patients were frail. The three most common frailty domains were comorbidity $(n=82,28 \%)$, polypharmacy $(n=37,13 \%)$ and malnutrition $(n=43,15 \%)$ (Table 3$)$. Overall, $73(25 \%)$ patients had a deficit in one mGA domain, $42(15 \%)$ in two domains and $25(9 \%)$ in three or more. The oncologists considered 15 patients (5\%) as frail and $89(31 \%)$ as intermediate,
Table 3. Frailty according to mGA category and median scores of the different scales

\begin{tabular}{|c|c|c|c|c|}
\hline & $\begin{array}{l}\text { No. } \\
\text { frail }\end{array}$ & $\%$ & $\begin{array}{c}\text { Median } \\
\text { (min, max) }\end{array}$ & $\begin{array}{l}\text { No. } \\
\text { missing }\end{array}$ \\
\hline $\begin{array}{l}\text { Nutritional status, } \\
\text { malnutrition }^{\text {a }}\end{array}$ & 43 & 15 & & 24 \\
\hline Comorbidity (OARS > 3) & 82 & 28 & $3(0-9)$ & 1 \\
\hline $\begin{array}{l}\text { Medications, } \\
\text { polypharmacy }(>7)\end{array}$ & 37 & 13 & $4(0-13)$ & 0 \\
\hline Falls $(\geqslant 2)$ & 10 & 3 & & 1 \\
\hline Activities of daily living ${ }^{b}$ & 12 & 4 & & 5 \\
\hline $\begin{array}{l}\text { Depressive symptoms } \\
(\mathrm{GDS} \geqslant 7)\end{array}$ & 35 & 12 & $2(0-13)$ & 4 \\
\hline $\begin{array}{l}\text { Physical function } \\
\text { (TUG }>14 \mathrm{~s} \text { ) }\end{array}$ & 18 & 6 & $8(4-25)$ & 13 \\
\hline $\begin{array}{l}\text { Cognitive function } \\
\text { (MMSE }<24 \text { ) }\end{array}$ & 9 & 3 & $29(19-30)$ & 0 \\
\hline $\begin{array}{l}\text { Frail according to any } \\
\text { category }\end{array}$ & 140 & 49 & & \\
\hline
\end{tabular}

giving a total of 104 (36\%) onc-frail according to the dichotomised classification.

According to both classifications, there were significantly more patients with good PS and curative treatment among the non-frail than among the frail (Table 2). For the oncologists' classification, there were significant differences in cancer type and stage of disease between frail and non-frail patients, i.e., the most frequent cancer types were lung cancer in the onc-frail group and colorectal 
cancer in the onc-non-frail group. The onc-non-frail group also comprised significantly more patients with localised disease (Table 2). When comparing the mGA-frail and mGA-non-frail patients, similar findings with significantly more frequent lung cancer in the mGA-frail group was found for cancer type.

In the small subgroup classified as frail by the oncologists in the original threefold classification, all patients had a poor PS. All but one had PS 2-4, and of the six patients in the overall cohort with PS 3-4, five belonged to this group. Otherwise their characteristics were similar to the overall onc-frail cohort: The most common diagnosis was lung cancer (33\%), the majority had metastatic disease (67\%), and none received treatment with curative intention.

The mGA-frail/mGA-non-frail classification coincided with the onc-frail/onc-non-frail classification for 187 (65\%) patients; 72 (25\%) patients were found mGA-frail and onc-frail, while $115(40 \%)$ patients were mGA-non-frail and onc-non-frail. A total of 67 (23\%) patients were classified as mGA-frail, but judged by the clinicians to be fit. In comparison to those who were both mGA-frail and oncfrail, this group included fewer patients with lung cancer (15\% vs $35 \%)$, and PS $2-4$ ( $0 \%$ vs $44 \%)$, but larger proportions of patients with colorectal cancer (39\% vs 17\%), localised disease (30\% vs 14\%), PS $0 \quad(61 \%$ vs $3 \%)$ and curative treatment (33\% vs $13 \%)$ (Supplementary material). Hence, favourable cancer-related prognostic factors were more frequent among these 67 patients. In terms of mGA deficits, the majority of these patients had one deficit ( $n=46,69 \%)$, whereas only $36 \%(n=26)$ had one deficit among those who were both mGA-frail and onc-frail. The most frequent mGA deficit missed by the oncologists was comorbidity. A total of 32 (11\%) patients were mGA-non-frail and onc-frail. The frequency of established, negative cancer-related prognostic factors (lung cancer, poor PS, advanced stages of disease, palliative treatment) was high in this group, similar to the group that was both mGA-frail and onc-frail.

The kappa statistic was 0.30 (95\% CI $0.19 ; 0.41)$, indicating only fair agreement between the oncologists' clinical judgement and the mGA.

OS according to frailty status. Median OS was 21.5 months, 93 (32\%) patients died within their first year of follow-up. Both mGAfrail and onc-frail patients had poorer median OS compared with mGA-non-frail and onc-non-frail patients, respectively (mGAfrail: 15.0 months, mGA-non-frail: 29.1 months; $P<0.001$ ) (oncfrail: 12.9 months, onc-non-frail: 27.4 months; $P<0.001$ ). The few patients $(5 \%)$ originally categorised as frail by the oncologists, had a median OS of only 7.4 months.

In bivariate Cox regression analyses, mGA-frail and onc-frail were both significantly negatively associated with OS (Table 4 and Figure $1 \mathrm{~A}$ and $\mathrm{B}$ ). The HR for mGA-frail was 1.86 (95\% CI 1.36; 2.56) $(P<0.001)$ and the HR for onc-frail was 1.94 (95\% CI 1.41; 2.66) $(P<0.001)$. In analyses adjusting for age, sex, cancer type, PS, stage and treatment, only mGA frailty was an independent negative prognostic factor for OS with a HR of 1.61 (95\% CI $1.14 ; 2.27$ ) $(P=0.007)$.

Finally, we explored possible differences in survival between four groups of patients; frail according to both assessments, nonfrail according to both assessments, frail according to only the mGA, and frail only according to our onc-frail definition. KaplanMeier OS curves of these four patient groups are presented in Figure 1C. The group classified as non-frail according to both assessments had the best OS and the group classified as frail according to both assessments had the poorest OS.

\section{DISCUSSION}

We found only fair agreement between frailty classified by a systematic, modified GA, and the oncologists' clinical judgement of frailty. The oncologists classified very few patients as frail, and even when pooling frail and intermediate patients (according to the oncologists), they missed almost half of the patients who were frail according to the mGA. The oncologists most commonly missed frailty due to comorbidity. Although both classification procedures succeeded in identifying patients with poorer survival, only mGAfrailty remained significantly associated to OS when other, established cancer related prognostic factors such as cancer type, stage, PS and treatment were taken into account.

The finding that physicians are more conservative in rating frailty than a systematic GA is in accordance with the results of others (Wedding et al, 2007; Tucci et al, 2009). To the best of our knowledge, no former study of cancer patients has reported the prognostic value of frailty rated merely by the oncologists' clinical judgement. Consistent with our findings, a study found physicianrated health to be prognostic for survival (Clough-Gorr et al, 2010). In that study, however, being considered moderately ill/severely ill by the physician was an independent prognostic factor. As only breast cancer patients with stage I-III were included, and neither PS nor treatment was taken into account, differences in patient populations and analyses may explain why the results were somewhat different from ours. The prognostic importance of being mGA frail is consistent with previous studies (Basso et al, 2008; Tucci et al, 2009; Ommundsen et al, 2014).

Our results suggest that the oncologists emphasise cancer-related factors when asked to rate frailty. Unfavourable prognostic factors such as lung cancer and advanced stage of disease were significantly more frequent in the onc-frail group compared with the onc-non-frail. The prognostic value of the oncologists' frailty assessment was not independent of other well-established prognostic factors. Furthermore, established negative cancer related prognostic factors were frequent among patients who were classified as onc-frail and not mGA frail, whereas the opposite was the case for those who were mGA-frail and onc-non-frail. Thus, the focus of the two classification procedures seemed to be different. Consequently, as demonstrated by our exploratory survival curves, the oncologists identified some patients with no mGA deficits and poor prognosis, whereas a larger group of patients who were frail according to mGA, and also had poorer prognosis compared to non-frail patients, was missed. This indicates that whereas the oncologists are experienced in evaluating cancer related health, training in identifying patients' overall vulnerability, including geriatric problems that may affect prognosis, is insufficient. Thus, increased education and awareness, and preferably inclusion of GA into routine clinical practice, may improve the physicians' ability to identify patients with otherwise unrecognised vulnerability (Wildiers et al, 2014), prevent undertreatment and harmful overtreatment, and reduce the frequency and severity of treatment-related adverse events. However, prospective studies are needed to investigate if GA followed by targeted interventions can improve cancer patients' prognosis and outcomes of therapy.

Strengths of this study are inclusion at multiple centres, a heterogeneous patient group with respect to type of cancer, stage of disease and planned treatment thus representative of a large group of patients commonly seen in clinical practice. The cohort is also fairly large compared with other studies investigating frailty in older cancer patients (Handforth et al, 2015). Our mGA included the main domains recommended for GA (Wildiers et al, 2014; Mohile et al, 2015), and we used well-known and validated scales (Folstein et al, 1975; Fillenbaum and Smyer, 1981; Yesavage et al, 1982; Podsiadlo and Richardson, 1991; Ottery, 1996; Persson et al, 1999). As patients needed to have deficits according to only one predefined criterion to be considered mGA-frail, we defined rather strict cutoff values in each of the domains included (Table 1) (Balducci and Extermann, 2000; Nitenberg and Raynard, 2000; Friedman et al, 2005; Cullum et al, 2006; Owusu et al, 2011; Klepin et al, 2014; Ommundsen et al, 2014; Jolly et al, 2015; Williams et al, 2015). Still, the validity of our mGA and chosen cutoff is open for discussion as 
Table 4. Cox regression analyses of the association between both frailty classifications and overall survival

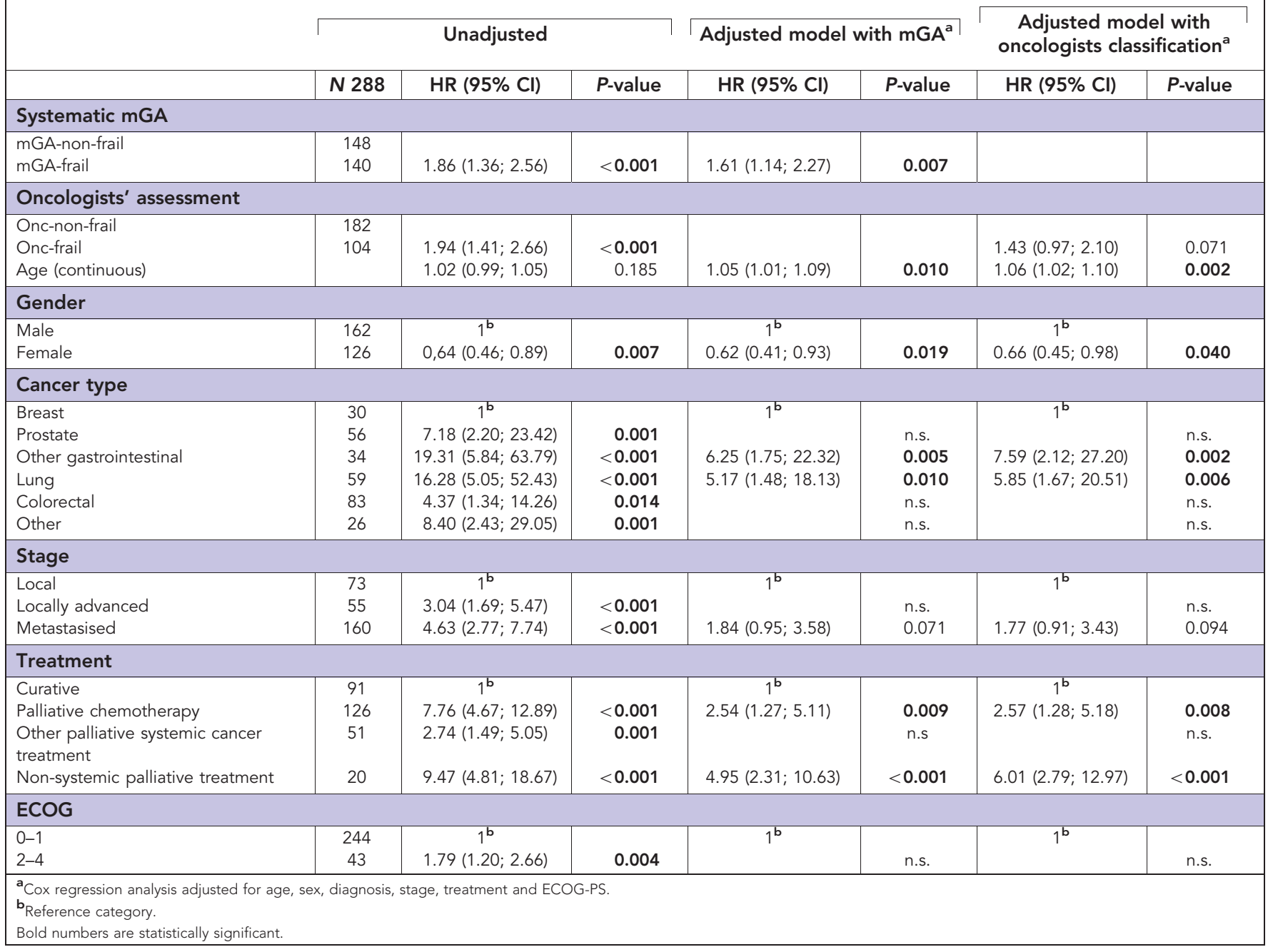

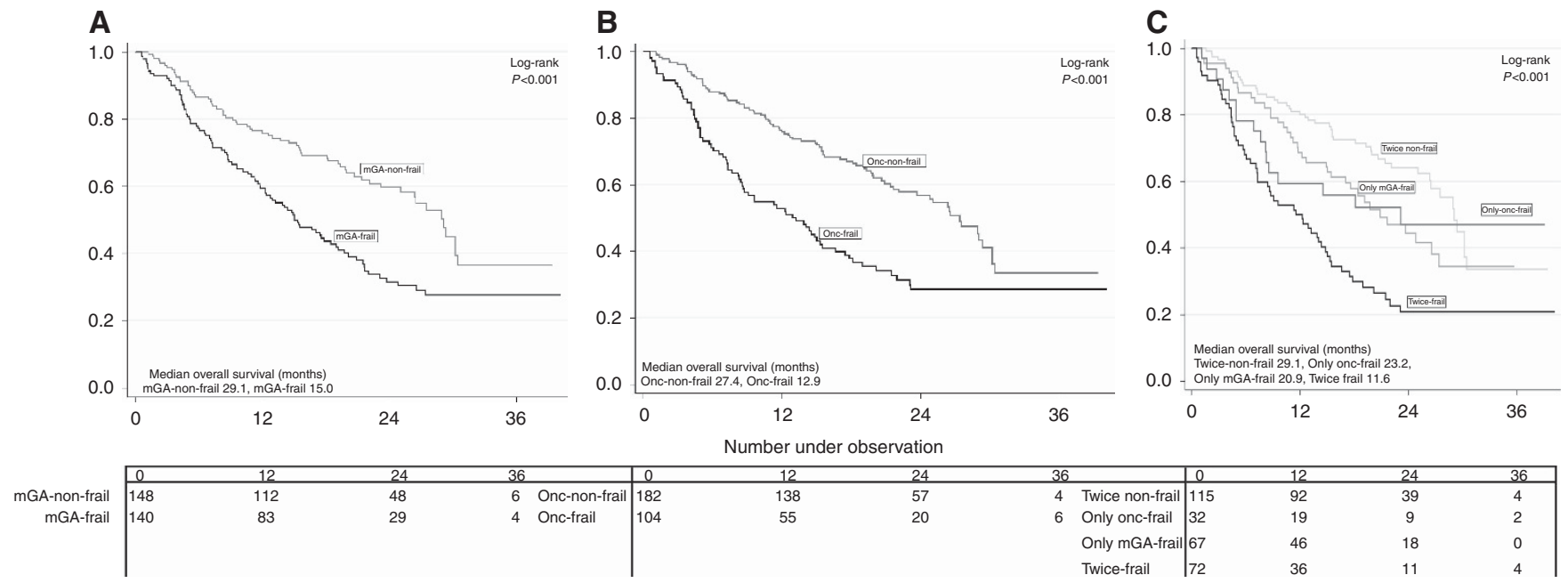

Figure 1. Kaplan Meier curves of overall survival (months) according to (A) mGA-non-frail/mGA frail, (B) onc-non-frail/onc-frail (C) both frailty classifications combined.

no gold standard currently exists (Handforth et al, 2015). More importantly, our definition of frailty may be questioned. It was, however, adapted from Balducci's criteria, and a similar approach has formerly been used and found superior to the physical phenotype of frailty in predicting post-operative complications in cancer patients, as well as being prognostic for survival (Kristjansson et al, 2012). We consider the inclusion of TUG as a frailty criterion is a potential strength rather than a weakness. Thus, the main objection may be the use of OARS for comorbidity registration, and that the severity of these conditions was not taken into account. 
Despite this, and although our comorbidity criterion was the most frequent reason for mGA frailty, we clearly demonstrate the independent prognostic value of our frailty measure. A frailty prevalence of $49 \%$ seems to be well within range of what has been observed in other studies (Handforth et al, 2015). Whether our definition actually capture the concept of frailty can, however, not be confirmed and the results should be interpreted with this in mind.

Another study limitation is the lack of data on eligible patients who were referred to the participating clinics and not included in our study. Furthermore, no information about the oncologists was systematically registered. Retrospectively, the participating clinics indicate that approximately 40 consultants evaluated from one to about 27-28 patients each, whereas 28 consultants are confirmed having assessed from one to seven of the mGA frail patients who were missed. An equal share of juniors and seniors with up to 30 years of oncology practice were represented. Thus, their oncological experience varied largely. This might, however, not be relevant when rating frailty. Insufficient training in assessing and managing geriatric syndromes is a widely recognised problem within several settings, including oncology (Hsu, 2016; Morris et al, 2017), and our prevalence of physician-rated frailty was similar to a study in which participating physicians had at least 10 years of clinical experience (Wedding et al, 2007). It should also be noted that dichotomising the oncologists' original threefold classification and thereby comparing a group identified as either intermediate or frail with mGA frail patients, may introduce a risk of misinterpreting the oncologists' assessments. Based on the difference in median survival between the frail patients and the overall cohort defined as onc-frail, there is no doubt that the oncologists were able to identify groups of patients with poor and very poor prognosis, respectively. However, for both groups, this prognostication seemed to be based on well-known negative cancer-related factors. Hence, the fact remains that the oncologists missed to identify a considerable number of patients with poor prognosis and frailty due to geriatric deficits.

In conclusion, our results demonstrate that a mGA can aid the oncologists in identifying otherwise unrecognised frail older patients' with poor prognosis, as well as those non-frail patients without geriatric deficits and thus a better prognosis. The oncologists using their clinical judgement are good at evaluating cancer related prognostic factors, but may need training in geriatric assessment to better assess patient's overall vulnerability and prognosis. A geriatric assessment may thus provide information contributing to oncologists making more appropriate treatment decisions for their old cancer patients.

\section{ACKNOWLEDGEMENTS}

This study was funded by Innlandet Hospital Trust and registered at clinicaltrials.gov (NCT01742442). We want to thank the cancer clinics at Innlandet Hospital Trust, Oslo University Hospital and Akershus University Hospital for their participation in the study. A special thanks to the study nurses at all locations who participated in the inclusion and assessment of patients.

\section{CONFLICT OF INTEREST}

The authors declare no conflict of interest.

\section{REFERENCES}

Aaronson NK, Ahmedzai S, Bergman B, Bullinger M, Cull A, Duez NJ, Filiberti A, Flechtner H, Fleishman SB, De Haes JC, Kaasa S, Klee M, Osoba D, Razavi D, Rofe PB, Schraub S, Sneeuw K, Sullivan M, Takeda F
(1993) The European Organization for Research and Treatment of Cancer QLQ-C30: a quality-of-life instrument for use in international clinical trials in oncology. J Natl Cancer Inst 85: 365-376.

Balducci L, Extermann M (2000) Management of cancer in the older person: a practical approach. Oncologist 5: 224-237.

Basso U, Tonti S, Bassi C, Brunello A, Pasetto LM, Scaglione D, Falci C, Beda M, Aversa SM, Stefani M, Castegnaro E, Tamellini F, Monfardini S (2008) Management of Frail and Not-Frail elderly cancer patients in a hospital-based geriatric oncology program. Crit Rev Oncol Hematol 66: 163-170.

Beauchet O, Fantino B, Allali G, Muir SW, Montero-Odasso M, Annweiler C (2011) Timed Up and Go test and risk of falls in older adults: a systematic review. J Nutr Health Aging 15: 933-938.

Cancer Research UK (2016) Cancer incidence by age. Available at http:// www.cancerresearchuk.org/health-professional/cancer-statistics/ incidence/age (accessed August 2016).

Clegg A, Young J, Iliffe S, Rikkert MO, Rockwood K (2013) Frailty in elderly people. Lancet 381: 752-762.

Clough-Gorr KM, Stuck AE, Thwin SS, Silliman RA (2010) Older breast cancer survivors: geriatric assessment domains are associated with poor tolerance of treatment adverse effects and predict mortality over 7 years of follow-up. J Clin Oncol 28: 380-386.

Cullum S, Tucker S, Todd C, Brayne C (2006) Screening for depression in older medical inpatients. Int J Geriatr Psychiatry 21: 469-476.

Fillenbaum GG, Smyer MA (1981) The development, validity, and reliability of the OARS multidimensional functional assessment questionnaire. J Gerontol 36: 428-434.

Folstein MF, Folstein SE, Mchugh PR (1975) 'Mini-mental state'. A practical method for grading the cognitive state of patients for the clinician. J Psychiatr Res 12: 189-198.

Friedman B, Heisel MJ, Delavan RL (2005) Psychometric properties of the 15 -item geriatric depression scale in functionally impaired, cognitively intact, community-dwelling elderly primary care patients. J Am Geriatr Soc 53: 1570-1576.

Hamaker ME, Jonker JM, De Rooij SE, Vos AG, Smorenburg CH, Van Munster BC (2012) Frailty screening methods for predicting outcome of a comprehensive geriatric assessment in elderly patients with cancer: a systematic review. Lancet Oncol 13: e437-e444.

Handforth C, Clegg A, Young C, Simpkins S, Seymour MT, Selby PJ, Young J (2015) The prevalence and outcomes of frailty in older cancer patients: a systematic review. Ann Oncol 26: 1091-1101.

Hsu T (2016) Educational initiatives in geriatric oncology - Who, why, and how? J Geriatr Oncol 7: 390-396.

Huisingh-Scheetz M, Walston J (2017) How should older adults with cancer be evaluated for frailty? J Geriatr Oncol 8: 8-15.

Hurria A, Gupta S, Zauderer M, Zuckerman EL, Cohen HJ, Muss H, Rodin M, Panageas KS, Holland JC, Saltz L, Kris MG, Noy A, Gomez J, Jakubowski A, Hudis C, Kornblith AB (2005) Developing a cancer-specific geriatric assessment: a feasibility study. Cancer 104: 1998-2005.

Jolly TA, Deal AM, Nyrop KA, Williams GR, Pergolotti M, Wood WA, Alston SM, Gordon BB, Dixon SA, Moore SG, Taylor WC, Messino M, Muss HB (2015) Geriatric assessment-identified deficits in older cancer patients with normal performance status. Oncologist 20: 379-385.

Klepin HD, Pitcher BN, Ballman KV, Kornblith AB, Hurria A, Winer EP, Hudis C, Cohen HJ, Muss HB, Kimmick GG (2014) Comorbidity, chemotherapy toxicity, and outcomes among older women receiving adjuvant chemotherapy for breast cancer on a clinical trial: CALGB 49907 and CALGB 361004 (alliance). J Oncol Pract 10: e285-e292.

Kristjansson SR, Nesbakken A, Jordhoy MS, Skovlund E, Audisio RA, Johannesen HO, Bakka A, Wyller TB (2010) Comprehensive geriatric assessment can predict complications in elderly patients after elective surgery for colorectal cancer: a prospective observational cohort study. Crit Rev Oncol Hematol 76: 208-217.

Kristjansson SR, Rønning B, Hurria A, Skovlund E, Jordhøy MS, Nesbakken A, Wyller TB (2012) A comparison of two pre-operative frailty measures in older surgical cancer patients. J Geriatr Oncol 3: 1-7.

Magnuson A, Allore H, Cohen HJ, Mohile SG, Williams GR, Chapman A, Extermann M, Olin RL, Targia V, Mackenzie A, Holmes HM, Hurria A (2016) Geriatric assessment with management in cancer care: current evidence and potential mechanisms for future research. J Geriatr Oncol 7: 242-248.

Mohile SG, Velarde C, Hurria A, Magnuson A, Lowenstein L, Pandya C, O’Donovan A, Gorawara-Bhat R, Dale W (2015) Geriatric assessment- 
guided care processes for older adults: a delphi consensus of geriatric oncology experts. J Natl Compr Canc Netw 13: 1120-1130.

Morris L, Thiruthaneeswaran N, Lehman M, Hasselburg G, Turner S (2017) Are future radiation oncologists equipped with the knowledge to manage elderly patients with cancer? Int J Radiat Oncol Biol Phys 98: 743-747.

Nitenberg G, Raynard B (2000) Nutritional support of the cancer patient: issues and dilemmas. Crit Rev Oncol Hematol 34: 137-168.

Ommundsen N, Wyller TB, Nesbakken A, Jordhoy MS, Bakka A, Skovlund E, Rostoft S (2014) Frailty is an independent predictor of survival in older patients with colorectal cancer. Oncologist 19: 1268-1275.

Ottery FD (1996) Definition of standardized nutritional assessment and interventional pathways in oncology. Nutrition 12: S15-S19.

Owusu C, Koroukian SM, Schluchter M, Bakaki P, Berger NA (2011) Screening older cancer patients for a Comprehensive Geriatric Assessment: a comparison of three instruments. J Geriatr Oncol 2: 121-129.

Persson C, Sjoden PO, Glimelius B (1999) The Swedish version of the patientgenerated subjective global assessment of nutritional status: gastrointestinal vs urological cancers. Clin Nutr 18: 71-77.

Podsiadlo D, Richardson S (1991) The timed 'Up \& Go': a test of basic functional mobility for frail elderly persons. J Am Geriatr Soc 39: 142-148.

Savva GM, Donoghue OA, Horgan F, O'Regan C, Cronin H, Kenny RA (2013) Using timed up-and-go to identify frail members of the older population. J Gerontol A Biol Sci Med Sci 68: 441-446.

Schiller JH, Harrington D, Belani CP, Langer C, Sandler A, Krook J, Zhu J, Johnson DH (2002) Comparison of four chemotherapy regimens for advanced non-small-cell lung cancer. N Engl J Med 346: 92-98.

Soubeyran P, Bellera C, Goyard J, Heitz D, Cure H, Rousselot H, Albrand G, Servent V, Jean OS, Van Praagh I, Kurtz JE, Perin S, Verhaeghe JL, Terret C, Desauw C, Girre V, Mertens C, Mathoulin-Pelissier S, Rainfray M (2014) Screening for vulnerability in older cancer patients: the ONCODAGE Prospective Multicenter Cohort Study. PLoS One 9: e115060.
Syse A (2012) Cancer incidence, prevalence and survival in an aging Norwegian population. Norsk Epidemiologi 22: 109-120.

Tucci A, Ferrari S, Bottelli C, Borlenghi E, Drera M, Rossi G (2009) A comprehensive geriatric assessment is more effective than clinical judgment to identify elderly diffuse large cell lymphoma patients who benefit from aggressive therapy. Cancer 115: 4547-4553.

Wedding U, Kodding D, Pientka L, Steinmetz HT, Schmitz S (2007) Physicians' judgement and comprehensive geriatric assessment (CGA) select different patients as fit for chemotherapy. Crit Rev Oncol Hematol 64: 1-9.

Wildiers H, Heeren P, Puts M, Topinkova E, Janssen-Heijnen ML, Extermann M, Falandry C, Artz A, Brain E, Colloca G, Flamaing J, Karnakis T, Kenis C, Audisio RA, Mohile S, Repetto L, Van Leeuwen B, Milisen K, Hurria A (2014) International Society of Geriatric Oncology consensus on geriatric assessment in older patients with cancer. J Clin Oncol 32: 2595-2603.

Williams GR, Deal AM, Nyrop KA, Pergolotti M, Guerard EJ, Jolly TA, Muss HB (2015) Geriatric assessment as an aide to understanding falls in older adults with cancer. Support Care Cancer 23: 2273-2280.

Winograd CH, Gerety MB, Chung M, Goldstein MK, Dominguez FJR, Vallone R (1991) Screening for frailty: criteria and predictors of outcomes. J Am Geriatr Soc 39: 778-784.

Yesavage JA, Brink TL, Rose TL, Lum O, Huang V, Adey M, Leirer VO (1982) Development and validation of a geriatric depression screening scale: a preliminary report. J Psychiatr Res 17: 37-49.

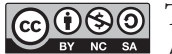

This work is licensed under the Creative Commons Attribution-Non-Commercial-Share Alike 4.0 International License. To view a copy of this license, visit http:// creativecommons.org/licenses/by-nc-sa/4.0/

(C) The Author(s) named above 2017

Supplementary Information accompanies this paper on British Journal of Cancer website (http://www.nature.com/bjc) 